\title{
Editor's Introduction
}

Everyone in the world knows that 2020 is unlike any other year. Coronavirus and COVID-19 have impacted communities large and small, with looming questions related to public and private health, education, and vaccinations. With the pandemic effecting layoffs and budget cuts, academics and researchers face uncertainties related to career advancement and research projects already underway. And yet, within the disruption lie opportunities for discovery. Social scientists, economists, and scholars of nearly every field will be pondering the impact of this global crisis for years to come. For those of us who study religion, we've been observing pandemic-related trends, especially about virtual worship and the social outreach of religious communities. We are revisiting the meaning of being "religious" when in-person gatherings are prohibited or severely restricted. We've noted that in most regions over time, religiosity is or has been high where infectious disease is prevalent. Although it will take time to amass proper data, we suspect a flurry of articles and commentary related to the impact of the pandemic on religious communities all the around the world. It remains to be seen how the current pandemic will influence religiosity, a topic of great relevance to the Journal of Religion and Demography.

For the Journal of Religion and Demography, we are particularly interested in how the pandemic's impact is felt differently across geographic spaces and religious traditions. For instance, how did a Christian-minority movement in say, China, fare compared to a Christian-majority country like the United Kingdom? Or, comparing religions-how did Muslim communities react to the virus compared to Hindu? Along with demographers, we are interested to see how the pandemic might change trends in birth rates (with an anticipated 500 ,ooo fewer births in the United States, for example) ${ }^{1}$ and age structures of religious congregations (in light of a virus that disproportionately targets the elderly). Which religious groups will be impacted the most by these changes in fertility? We anticipate that future issues of the journal will tackle these pressing issues once the data become available.

1 Melissa S. Kearney and Phillip B. Levine, "Half a Million Fewer Children? The Coming Covid Baby Bust." The Brookings Institute, June 15, 2020, https://www.brookings.edu/research/half -a-million-fewer-children-the-coming-covid-baby-bust/, accessed August 6, 2020. 
In light of all the changes in 2020, religious communities have continued to function, albeit differently, and academics have continued to produce scholarship to help us understand religion's role in the world on a deeper level. This issue begins with one of the features of the Journal of Religion and Demography: Data for every religion (18 categories, including separate categories for agnostics and atheists) for the world and by continent-Africa, Asia, Europe, Latin America, Northern America, and Oceania-in 1970, 2000, 2020, and projections for 2030. Todd Johnson and Peter Crossing's analysis reveals that the world is becoming more religious over time, from $80.8 \%$ of the world's population belonging to a religion in 1970 to $90 \%$ by 2030. Muslims have grown the fastest of all religions, growing from $15.4 \%$ of the world's population in 1970 to $24.3 \%$ in 2020 .

In addition to these data, this volume tackles three pressing issues related to religion in the world today: environmental change, immigration, and gender. Vegard Skirbekk, Alex deSherbinin, Susana Beatriz Adamo, Jose Navarro, and Tricia Chai-Onn provide a compelling world study of religious affiliation and environmental change, helping to fill a gap in religious studies. The team conducted exploratory and descriptive statistical analyses to better understand the associations among religion and economic development, greenhouse gas emissions, exposure to environmental stressors with attitudes, beliefs, and environmental performance. They found that countries with lower population shares and high religious affiliation tend to have more emissions and low or negative population growth, but, they are also better prepared for environmental challenges. Morten Blekesaune investigates an important and continuing trend in the demography of religion by investigating fertility rates among immigrants to Europe. Using data from the European Social Survey, Blekesaune found that many immigrants have fertility outcomes that converge towards the native fertility of their country of residence in Europe by a surprisingly strong factor. However, immigrants from Muslim countries have higher fertility and compress their fertility over fewer years than immigrants from Christian countries. Finally, Daniel Chen offers a unique perspective on another pressing issue of human need: gender inequality and violence. His study of marriage contracts in the United States and China builds and tests a model of marriage as an incomplete contract that arises from asymmetric virginity premiums, the inequality between men and women's ex ante and ex post marriage market opportunities. This study could be influential for how governments, international organizations, and NGOs approach gender relations within marriages.

We hope that the Journal of Religion and Demography can continue to offer new quantitative analyses of religion and non-religion worldwide, despite the 
challenges that continue to arise. We reaffirm our commitment to helping produce scholarship from around the globe, from younger scholars, and for lessstudied religions and regions.

Gina Zurlo (Boston)

Vegard Skirbekk (Oslo)

October 2020 